\title{
Demarcated opacity in primary teeth increases the prevalence of molar incisor hypomineralization
}

Magdalena Raquel Torres REYES(a)

Aluhê Lopes FATTURI(a) (iD

José Vitor Nogara Borges MENEZES(a)

Fabian Calixto FRAIZ(a)

Luciana Reichert da Silva

ASSUNÇÃO(a)

Juliana Feltrin de SOUZA(a)

(a) Universidade Federal do Paraná - UFPR, School of Dentistry, Department of Stomatology, Curitiba, PR, Brazil.

Declaration of Interests: The authors certify that they have no commercial or associative interest that represents a conflict of interest in connection with the manuscript.

Corresponding Author:

Juliana Feltrin de Souza

E-mail: julianafeltrin@hotmail.com

hitps://doi.org/10.1590/1807-3107bor-2019.vol33.0048

Submitted: October 29, 2018

Accepted for publication: April 8, 2019

Last revision: May 9, 2019
Abstract: This cross-sectional study aimed to assess the prevalence of molar incisor hypomineralization (MIH) and its relationship with the number of primary teeth with developmental defects of enamel (DDE). A representative population-based sample of 731 schoolchildren was randomly selected from the public school system in Curitiba, Brazil. Schoolchildren aged 8 years with fully erupted permanent first molars and incisors were eligible for the study. MIH and DDE were classified by four calibrated examiners (kappa $>0.75$ ) according to EAPD criteria and to the FDI-modified DDE index. Clinical data were collected in a school environment. Socioeconomic information was collected through a self-administered semistructured questionnaire applied to the children's caregivers. Statistical analyses were carried out using Poisson multiple regression with robust variance $(\alpha=0.05)$. MIH prevalence was $12.1 \%$ (95\%CI: 10-15), and opacities were the most prevalent defect. Socioeconomic factors were not associated with MIH. Children with demarcated opacity in primary teeth presented a higher prevalence of MIH than those without DDE in primary teeth. In the multiple analysis, the increase of one primary tooth affected by demarcated opacity increased the prevalence of $\mathrm{MIH}$ by $33 \%$ ( $\mathrm{PR}=1.33,95 \% \mathrm{CI}$ : 1.15-1.53, $\mathrm{p}<0.001)$. Asian children had a higher prevalence of $\mathrm{MIH}(\mathrm{PR}=2.91$, 95\%CI: 1.08-8.09 $\mathrm{p}=0.035)$ than did Caucasian children. Conclusion: Based on these findings, the prevalence of $\mathrm{MIH}$ in Curitiba was $12.1 \%$. Demarcated opacity in primary teeth could be considered a predictor of MIH.

Keywords: Dental Enamel Hypoplasia; Tooth, Decicuous; Epidemiologic Studies.

\section{Introduction}

Molar incisor hypomineralization (MIH) was described in Sweden in 1970, and the term was standardized by the European Academy of Pediatric Dentistry (EAPD) in 2003. It consists of a specific qualitative developmental defect of enamel (DDE), clinically characterized by demarcated opacities that affect first permanent molars and occasionally involves permanent incisors. ${ }^{1}$ The changes in the enamel structure are asymmetric between the dental arches and may range from enamel opacities to large structural losses requiring dental intervention. ${ }^{2} \mathrm{MIH}$ 
prevalence presented in the literature varies across different countries from $6.3 \%$ in India ${ }^{8}$ to $40.2 \%$ in Brazil. ${ }^{3}$ In a review study, MIH has shown a high prevalence globally. ${ }^{4}$

Similar clinical characteristics of $\mathrm{MIH}$ are also observed in primary teeth..$^{5,6}$ Demarcated opacity in second primary molars has been defined as hypomineralization of second primary molars (HSPM). ${ }^{7}$ It presents from one to four second primary molars. Studies report HSPM prevalence between 0 and $21.8 \%$ across different countries. ${ }^{78}$ In primary teeth, the prevalence of all types of DDE ranges from $4.6 \%$ in Nigeria ${ }^{9}$ to $48.0 \%$ in Brazil. ${ }^{10}$ These DDE have been observed in canines and in primary molars, and a significant association with MIH has been shown. 5,6,8 This fact can be associated with the overlap of dental development periods and mineralization of canines, first and second primary molars, and first permanent molars; however, it is important to highlight that the enamel maturation process is relatively larger in permanent molars. ${ }^{5,11,12}$

A recent systematic review found that the presence of HSPM is predictive of $\mathrm{MIH}$, and that the association between defects appears more important in the presence of mild HSPM, with demarcated opacities in second primary molars as a predictor of an increased risk for $\mathrm{MIH}^{13}$

The study of MIH and its relationship with DDE in primary teeth is fundamental since it is possible to identify a high-risk group for $\mathrm{MIH}$, allowing for the earlier diagnosis of MIH. Enamel defects are highly frequent in clinical practice, presenting higher susceptibility to dental caries, ${ }^{14}$ and more complex dental care. They may be associated with large fractures of the tooth structure, sensitivity, difficulty in the bonding of restorative materials, and need for retreatment. ${ }^{2,15,16,17}$ To the best of our knowledge, MIH prevalence in southern Brazilian cities and towns has not been investigated yet. The literature has evaluated the association between HSPM and $\mathrm{MIH}$. The purpose of the present study is to analyze not only the prevalence of both enamel defects, but also to test whether the prevalence of MIH could be influenced by the number of primary teeth (molars and canines) affected by DDE, mainly by hypoplasia and demarcated opacity.

\section{Methodology}

This cross-sectional study was approved by the Research Ethics Committee of Health Sciences of the Universidade Federal do Paraná (1.613.829 / 2016). After approval, schoolchildren and their parents or legal guardians signed an informed consent form for their participation in the study. This study was reported according to the STROBE statement for observational studies (https://www.strobe-statement.org).

\section{Sampling}

The study participants were selected from public schools in Curitiba, state capital of Paraná, Brazil, which has a population of 1,908,359 inhabitants. In 2016, Curitiba had 143,701 children aged 8 years enrolled in the public school system, according to 2010 data from the Brazilian Institute of Geography and Statistics, ${ }^{18}$ and a Human Development Index (HDI) of 0.823 , ranking in $10^{\text {th }}$ place among Brazilian cities and towns according to the United Nations Development Program (UNDP).

In order to obtain a representative sample, sample size was calculated with a finite population, the proportion of DDE in this population was set at $50 \%$, an accuracy of $5 \%$ was used, a design effect factor of 1.8 was established for cluster sampling, and a boundary of $1.96(20 \%)$ for the rejection area was added to compensate for occasional losses, resulting in a final sample of 690 to 865 children.

The sample was selected based on the proportion of schoolchildren in nine health districts of Curitiba. The sampling process used two-stage clustering. First, two schools were randomly selected from each health district, and schoolchildren from those schools were subsequently chosen at random. The randomizations were obtained from www.randomizer.org.

Schoolchildren whose parents or legal guardians had signed the informed consent form were eligible for the study. Schoolchildren wearing orthodontic braces were excluded from the study because visualization would be impaired. Schoolchildren with anodontia, oligodontia, and amelogenesis imperfecta were also excluded. 


\section{Pilot study}

A pilot study was conducted with 80 school children, in the same age range as those of the main study, from the municipal public school system. The clinical examination was performed under the same conditions and criteria established in the main study. Questionnaires were also applied to parents or legal guardians in order to evaluate the understanding and possible changes in the proposed methods. Participants from the pilot study were not included in the sample.

\section{Data collection}

Four examiners underwent training and calibration protocols for collection of clinical data on DDE and MIH, using the modified DDE inde ${ }^{19}$ and the MIH criteria established by the European Academy of Pediatric Dentistry (EAPD). ${ }^{20}$ Demarcated opacity, diffuse opacity, and hypoplasia were assessed in the case of DDE, and demarcated opacity (white, yellow, or brown), post-eruptive fracture (involving enamel or enamel and dentin), atypical restoration (satisfactory or unsatisfactory), and exodontia were used for assessment of MIH. Thirty intraoral photographs of DDE in primary teeth were selected, and the clinical characteristics and situations associated with the differential diagnosis were discussed. After that, 60 different photographs, involving all the different clinical manifestations of DDE, were selected and analyzed independently by the examiners. ${ }^{19}$ One week later, the examiners (duplicate examination) independently analyzed the same photographs in a different order. For estimation of the interrater reliability, the obtained scores were compared with the reference standard from an expert examiner. The objective of calibration was to achieve good to excellent interrater and intrarater reliability (kappa $\geq 0.75$ ). Intrarater and interrater kappa values were $\geq 0.75$.

The clinical data were collected in a school environment, under artificial lighting conditions, using a mouth mirror, a blunt-tipped WHO probe, and sterile gauze. Only demarcated opacities greater than $1.0 \mathrm{~mm}$ in diameter were considered, ${ }^{20}$ and the differential diagnosis between them and white spot lesions was based on the criteria proposed by Seow. ${ }^{21}$ The data were collected between November 2016 and September 2017.

A semistructured questionnaire was applied to children's parents or legal guardians to gather socioeconomic information, including sex, age, self-reported ethnicity, marital status, family structure, number of household members, monthly family income, and parental level of education.

\section{Statistical analysis}

Independent variables were categorized and analyzed descriptively. Family structure was dichotomized into nuclear, when there was a stable relationship between parents or legal guardians, and non-nuclear, when parents or legal guardians were single or widowed. Family income was dichotomized based on the median of the sample into $\leq 2$ Brazilian monthly minimum wages (BMMW) and > 2 BMMW. The level of education of parents or legal guardians was dichotomized into $\leq 8$ years and $>8$ years of schooling. Ethnicity was self-reported by parents or legal guardians.

For the prevalence rates and association analysis, DDE and MIH variables were dichotomized into present and absent. The presence of MIH was computed when at least one first permanent molar was affected by hypomineralization. The presence of DDE in primary teeth was computed when at least one primary tooth was affected by hypoplasia or demarcated opacity. A Poisson multiple regression model with robust variance was built to evaluate the relationship between MIH and DDE in primary teeth. Independent variables with $p$-value $<0.20$ in the univariate regression analysis were included in the model according to the stepwise forward selection. For the multiple model, DDE in primary teeth was computed as a quantitative variable, considering the number of primary teeth affected by demarcated opacities. Statistical Package for Social Sciences for Windows, version 19.0 (SPSS Inc., Chicago, USA), and STATA (version 14.0; Stata Corp. LLC, College Station, TX, USA) were used for the statistical analyses. 


\section{Results}

A total of 784 pairs of children and parents or legal guardians agreed to participate in the study. Of these, 733 children were examined, 51 children were not present on the day when the data were collected, and two children were excluded from the study

Table 1. Socioeconomic characteristics of 8-year-old schoolchildren in the city of Curitiba, Brazil, 2017 ( $n=731)$.

\begin{tabular}{|c|c|}
\hline Characteristics & n (\%) \\
\hline \multicolumn{2}{|l|}{ Sex } \\
\hline Male & $374(51.16)$ \\
\hline Female & $357(48.84)$ \\
\hline \multicolumn{2}{|l|}{ Ethnicity } \\
\hline Caucasian & $617(84.40)$ \\
\hline Afro-descendant & $89(12.18)$ \\
\hline Asian & $11(1.50)$ \\
\hline Indigenous & $14(1.92)$ \\
\hline \multicolumn{2}{|l|}{ Family BMW } \\
\hline$>2 \mathrm{BMW} \mathrm{R} \$$ per month & $258(35.3)$ \\
\hline$<2$ BMW R $\$$ per month & $473(64.7)$ \\
\hline \multicolumn{2}{|c|}{ Mean: 2.000 .26 SD $=1660.94$} \\
\hline \multicolumn{2}{|l|}{ Schooling } \\
\hline$>8$ years & $518(71.65)$ \\
\hline$\leq 8$ years & $205(28.35)$ \\
\hline \multicolumn{2}{|c|}{ Number of household members } \\
\hline$<4$ & $487(66.62)$ \\
\hline$\geq 5$ & $244(33.38)$ \\
\hline \multicolumn{2}{|l|}{ Family structure } \\
\hline Nuclear family & $501(69.58)$ \\
\hline Non-nuclear family & $219(30.42)$ \\
\hline \multicolumn{2}{|l|}{ Health districts } \\
\hline Matriz & $24(3.28)$ \\
\hline Cajuru & $95(13)$ \\
\hline Bairro Novo & $89(12.18)$ \\
\hline Boqueirão & $85(11.63)$ \\
\hline Pinheirinho & $130(17.78)$ \\
\hline Boa vista & 95 (13) \\
\hline Portão & $54(7.39)$ \\
\hline $\mathrm{ClC}$ & $104(14.23)$ \\
\hline Santa Felicidade & $55(7.52)$ \\
\hline
\end{tabular}

Note: BMW: Brazilian minimum wage in Reais per month; Nuclear families: when there was a stable relationship between parents or legal guardians, and non-nuclear, when parents or legal guardians were single or widowed. for wearing orthodontic braces. Therefore the final sample consisted of 731 children. The socioeconomic and demographic data are presented in Table 1.

MIH prevalence was $12.1 \%(n=88,95 \% C I$ : $10-15)$. There was a higher prevalence of MIH in tooth 46 (8.1\%), followed by tooth $36(7.5 \%)$, tooth $16(6.5 \%)$, and tooth 26 (5.7\%). In incisors, MIH prevalence was higher in tooth $11(4 \%)$, followed by tooth 21 (2.3\%). Regarding the severity of $\mathrm{MIH}$, demarcated opacities were the most prevalent defects $(8.6 \%$ for yellow opacity, $7.3 \%$ for white opacity, and $1.9 \%$ for brown opacity), followed by loss of structure (1.2\% in enamel and $1.2 \%$ in enamel and dentin) and atypical restorations (satisfactory in $0.8 \%$ and unsatisfactory in $0.7 \%$ ).

DDE prevalence in primary teeth (demarcated opacity and/or hypoplasia) was $13.7 \%(\mathrm{n}=100)$. Among the evaluated types of DDE, demarcated opacity was the most prevalent, affecting $12.5 \%$ of the total sample, whereas the prevalence of dental hypoplasia was $1.8 \%$ (Table 2). The higher prevalence of demarcated hypomineralization was observed in second primary molars (4.4\% for tooth $85,3.8 \%$ for tooth

Table 2. Prevalence of molar incisor hypomineralization (MIH) and developmental defects of enamel (DDE) in primary teeth according to severity (Curitiba, Brazil, 2017).

\begin{tabular}{lcc}
\hline MIH & & \\
\hline \multirow{2}{*}{ Severity } & PRESENT & ABSENT \\
\cline { 2 - 3 } & $\mathrm{n}(\%)$ & $\mathrm{n}(\%)$ \\
\hline White opacity & $53(7.3)$ & $678(92.7)$ \\
Yellow opacity & $63(8.6)$ & $668(91.4)$ \\
Brown opacity & $14(1.9)$ & $717(98.1)$ \\
Loss of structure (enamel) & $12(1.2)$ & $719(98.4)$ \\
Loss of structure (enamel and dentin) & $9(1.2)$ & $722(98.8)$ \\
Atypical restorations - satisfactory & $6(0.8)$ & $725(99.2)$ \\
Atypical restorations - unsatisfactory & $5(0.7)$ & $726(99.3)$ \\
Atypical extraction & $0(0.0)$ & $0(0.0)$ \\
MIH with incisor involvement & $48(6.6)$ & $683(93.4)$ \\
DDE in primary teeth & & \\
DDE & PRESENT & ABSENT \\
Demarcated opacity & $\mathrm{n}(\%)$ & $\mathrm{n}(\%)$ \\
Hypoplasia & $90(12.5)$ & $631(87.5)$ \\
\hline & $13(1.8)$ & $718(98.2)$ \\
\hline
\end{tabular}


$75,4.2 \%$ for tooth 55 , and $2.2 \%$ for tooth 65 ), followed by canines, which were the most severely affected teeth in the primary dentition, with the prevalence of demarcated opacity ranging from $1.0 \%$ to $1.8 \%$.

Table 3 shows the crude PR (cPR) for MIH considering the characteristics of the sample. There is a significant association between the presence of DDE in primary teeth and MIH. The presence of demarcated opacity significantly increased the prevalence of $\mathrm{MIH}(\mathrm{cPR}=2.12$ 95\% CI: 1.35-3.28; $\mathrm{p}=0.001$ ), and the higher the number of primary teeth with demarcated opacity, the higher the prevalence of $\mathrm{MIH}$ (cPR $=1.32$ 95\% CI: 1.15-1.52, p < 0.001). MIH was not associated with socioeconomic factors. In the bivariate analysis, indigenous and Asian ethnicities tend to have a higher prevalence of $\mathrm{MIH}$.

Table 3. Crude Prevalence ratio (cPR) of MIH according to DDE in primary teeth and socioeconomic characteristics of the sample (Curitiba, Brazil, 2017).

\begin{tabular}{|c|c|c|c|c|}
\hline \multirow{2}{*}{ Characteristics } & \multicolumn{2}{|c|}{$\mathrm{MlH}$} & \multirow{2}{*}{ CPR $(95 \% \mathrm{Cl})$} & \multirow{2}{*}{$\mathrm{p}$-value } \\
\hline & YES (\%) & NO (\%) & & \\
\hline \multicolumn{5}{|l|}{ Sex } \\
\hline Female & 39 (10.9) & $318(89.1)$ & reference & \multirow{2}{*}{0.366} \\
\hline Male & $49(13.1)$ & $325(86.9)$ & $1.19(0.80-1.78)$ & \\
\hline \multicolumn{5}{|l|}{ Ethnicity } \\
\hline Caucasian & $69(11.2)$ & $548(88.8)$ & reference & \multirow{2}{*}{0.521} \\
\hline Afro-descendant & $12(13.5)$ & $77(86.5)$ & $1.20(0.68-2.13)$ & \\
\hline Asian & $3(27.3)$ & $8(72.7)$ & $2.34(0.90-6.56)$ & 0.078 \\
\hline Indigenous & $4(28.6)$ & $10(71.4)$ & $2.55(1.08-6.02)$ & 0.032 \\
\hline \multicolumn{5}{|l|}{ Family BMW } \\
\hline$>2 \mathrm{BMW}$ & $25(9.69)$ & $233(90.31)$ & reference & \multirow{2}{*}{0.155} \\
\hline$\leq 2 \mathrm{BMW}$ & $63(13.32)$ & $410(86.68)$ & $1.37(0.88-2.13)$ & \\
\hline \multicolumn{5}{|l|}{ Schooling } \\
\hline$>8$ years & $66(12,7)$ & $452(87.3)$ & reference & \multirow{2}{*}{0.264} \\
\hline$\leq 8$ years & $20(9.8)$ & $185(90,2)$ & $0.76(0.47-1.22)$ & \\
\hline \multicolumn{5}{|l|}{ Number of household members } \\
\hline$<4$ & $56(11.5)$ & $461(88.5)$ & reference & \multirow{2}{*}{0.526} \\
\hline$\geq 5$ & $32(13,1)$ & $212(86,9)$ & $1.14(0.79-1.71)$ & \\
\hline \multicolumn{5}{|l|}{ Family structure } \\
\hline Nuclear family & $58(11,58)$ & $443(58,0)$ & reference & \multirow{2}{*}{0.645} \\
\hline Non-nuclear family & $28(12,8)$ & $191(87,2)$ & $1.10(0.72-1.68)$ & \\
\hline \multicolumn{5}{|l|}{ DDE in primary teeth } \\
\hline No & $66(10.5)$ & $565(89.5)$ & Reference & \multirow{2}{*}{$<0.001$} \\
\hline Yes & $22(22.0)$ & 78 (78.0) & $2.10(1.36-3.24)$ & \\
\hline \multicolumn{5}{|l|}{ Demarcated opacity } \\
\hline No & $66(10.5)$ & $565(89.5)$ & Reference & \multirow{2}{*}{0.001} \\
\hline Yes & $20(22.2)$ & $70(77.8)$ & $2.12(1.35-3.28)$ & \\
\hline \multicolumn{5}{|l|}{ Hypoplasia } \\
\hline No & $86(12.0)$ & $632(88.0)$ & reference & \multirow{2}{*}{0.708} \\
\hline Yes & $2(15.4)$ & $11(84.6)$ & $1.28(0.35-4.67)$ & \\
\hline \multirow{2}{*}{$\begin{array}{l}\text { Number of teeth with demarcated opacity } \\
\text { (Mean SD, min-max) }\end{array}$} & Mean (SD) & $\min -\max$ & \multirow{2}{*}{$1.32(1.15-1.52)$} & \multirow{2}{*}{$<0.001$} \\
\hline & $0.22(0.73)$ & 0-7 & & \\
\hline
\end{tabular}

Note: Crude Prevalence ratio (cPR) calculated by Poisson regression analysis. Level of significance: 0.05 . 
Table 4.- Adjusted prevalence ratio ( $\left.{ }_{a} \mathrm{PR}\right)$ of $\mathrm{MIH}$ according to number of DDE in primary teeth and socioeconomic characteristics of the sample. (Curitiba, Brazil, 2017).

\begin{tabular}{|c|c|c|}
\hline \multirow{2}{*}{ Characteristics } & \multicolumn{2}{|c|}{$\mathrm{MIH}$} \\
\hline & aPR (95\%Cl) & $\mathrm{p}$-value \\
\hline \multicolumn{3}{|l|}{ Ethnicity } \\
\hline Caucasian & reference & \\
\hline Afro-descendant & $1.19(0.66-2.14)$ & 0.549 \\
\hline Asian & $2.91(1.08-8.09)$ & 0.035 \\
\hline Indigenous & $2.09(0.73-5.96)$ & 0.168 \\
\hline \multicolumn{3}{|l|}{ Family BMW } \\
\hline$>2 \mathrm{BMW}$ & reference & \multirow{2}{*}{0.147} \\
\hline$\leq 2 \mathrm{BMW}$ & $1.38(0.89-2.16)$ & \\
\hline $\begin{array}{l}\text { Number of teeth with } \\
\text { demarcated opacity }\end{array}$ & $1.33(1.15-1.53)$ & $<0.001$ \\
\hline
\end{tabular}

Table 4 shows the adjusted prevalence rate of $\mathrm{MIH}$ in relation to DDE, considering ethnicity and per capita income. The increase of one primary tooth affected by demarcated opacity increased the prevalence of $\mathrm{MIH}$ by $33 \%(\mathrm{aPR}=1.33,95 \% \mathrm{CI}$ : 1.15-1.53, $\mathrm{p}<0.001)$. Asian children had a higher prevalence of $\mathrm{MIH}(\mathrm{aPR}=2.91,95 \% \mathrm{CI}: 1.08-8.09$ $\mathrm{p}=0.035)$ than did Caucasian children.

\section{Discussion}

The MIH prevalence found in the present study was $12.1 \%$ (95\% CI 10-15), which is in line with the findings obtained for other South American populations., ${ }^{3,14,22}$ Similar rates were also observed in Bosnia and Herzegovina (12.3\%), ${ }^{23}$ Singapore $(12.5 \%),{ }^{24}$ and Iran (12.7\%). ${ }^{25}$ According to these prevalence data, MIH could be considered a public health problem, once teeth with $\mathrm{MIH}$ are the ones with greater need of preventive, restorative, endodontic, extraction, or orthodontic treatments. ${ }^{15}$ Moreover, children with MIH make more visits to the dentist. ${ }^{26}$ In our sample, $3.1 \%$ of the children needed restorative treatment for permanent teeth due to MIH. Previous studies ${ }^{27,28}$ have reported that yellow and brown opacities in first permanent molars were at a higher risk for fracture or for carious lesions. Neves et al. ${ }^{28}$ observed that $14 \%$ of white opacities and $27.5 \%$ of yellow opacities maximized the likelihood of enamel breakdown, exposing the dentin. Thus, opacities should also be preventively treated, either with fluoride application or sealants. ${ }^{33}$

$\mathrm{MIH}$ is considered a systemic pathology due to the involvement of permanent first molars and incisors within a similar chronological period. ${ }^{1}$ The asymmetrical pattern of MIH in molars suggests that ameloblasts are affected by a systemic disorder at a very specific stage of their development. ${ }^{12}$ This could result in enamel defects not only in permanent first molars and incisors, but also in primary teeth, due to the similar chronological period. The literature has shown an association between DDE in primary teeth and $\mathrm{MIH}$, especially in the case of HSPM. In a recent systematic review that included a meta-analysis, HSPM was deemed to be a predictor of MIH with an overall odds ratio of 4.66 (95\%CI: 2.11-10.26; p < 0.001). ${ }^{13}$

Unlike the previous studies reported in a systematic review, ${ }^{14}$ the present study found not only this association in second primary molars, but also a significant increase in the prevalence of MIH according to the number of primary teeth with demarcated opacities. The increase of one primary tooth with demarcated opacity increased the prevalence of $\mathrm{MIH}$ by 33\%, regardless of other variables. Although MIH was defined as a specific enamel defect in permanent first molars and incisors, these findings suggest that similar demarcated opacities could have affected other teeth than second primary teeth, depending on the severity of the exposure.

The association of MIH with demarcated opacity in primary teeth has been previously described. Da Silva et al. ${ }^{6}$ observed that Brazilian children with opacity in second primary molars or in primary canines were six times more likely to develop MIH. The association between demarcated opacity in primary teeth and $\mathrm{MIH}$, and their similar clinical characteristics, can be explained by the development of canines and primary molars concomitantly with the development of first permanent molars. Thus, it is suggested that systemic or environmental events combined with genetic ones in specific moments of dental development can alter the 
eruption of second primary molars and of first permanent molars, ${ }^{5,29}$ depending on the duration and/or severity of exposure.

Considering the distribution of the affected teeth, lower teeth were the most severely affected by MIH. These findings differ from those found for 12-year-old Chinese children, in whom maxillary first permanent molars were the most frequently affected by $\mathrm{MIH} .{ }^{30}$ This is in line with the findings of Temilola et al., who observed $\mathrm{MIH}$ in $60 \%$ of maxillary teeth and $40 \%$ in mandibular teeth. By evaluating enamel defects in second primary molars, it was observed that maxillary teeth were also the most frequently affected..$^{29}$ These differences can be explained by the chronology of dental development and by the length of exposure to risk factors. It is known that the eruption of mandibular teeth could occur earlier than that of maxillary ones, ${ }^{11}$ so younger children can be exposed to proportionally larger systemic insults than can older children.

The prevalence of $\mathrm{MIH}$ in incisors was $6.6 \%$, and maxillary incisors were more frequently affected than mandibular ones, as observed in a Saudi Arabian population of children aged 8-12 years, ${ }^{31}$ as well as in Chinese children with a mean age of 12 years. ${ }^{25}$ The definition of MIH establishes that incisors may be involved or affected and, when affected, they usually present mild involvement when compared to molars, with opacities that may need esthetic treatments, ${ }^{22}$ which are less invasive than the restorative treatments required by molars subjected to masticatory forces. This represents a greater risk of fracture of the hypomineralized enamel, leading to structural losses. It is known that more molars are affected by MIH and that the chance of hypomineralization in incisors is higher., ${ }^{3,32}$ It suggested that, in $6.6 \%$ of the sample, there could be a larger number of teeth with MIH.

Clinical characteristics in teeth affected by hypomineralization may vary in severity from opacities to structural losses or extensive atypical restorations. ${ }^{33}$ In the present study, demarcated opacities were the most prevalent manifestations of MIH, followed by loss of post-eruptive enamel and atypical restorations. Other studies have also shown demarcated opacities as the most prevalent manifestation of MIH. ${ }^{22,31,34}$ This finding can be explained by the age of the children examined (8 years), which is the ideal age for the diagnosis of MIH. ${ }^{35}$ At this age, there might be a relatively short time for permanent teeth to be exposed to masticatory forces and, consequently, to the risk of post-eruptive fractures. The cross-sectional design of the present study was a limitation because it only allows evaluating the real situation of children in a specific time period. Hence, prospective longitudinal studies are needed, since the severity of MIH is proportional to the increase in children's age. ${ }^{22}$ However, for this specific association between primary and permanent teeth, observed clinically, this limitation could be reduced by the age of the sample. Once the age of 8 years is considered the ideal age for the diagnosis of MIH in permanent teeth, as described previously, ${ }^{21}$ past events during tooth development (prenatal and postnatal periods) could be observed by DDE in primary teeth (in canines and molars) at this age.

In the present study, the prevalence of DDE in primary teeth (demarcated opacity and/or hypoplasia) was $13.7 \%$, with demarcated opacity as the most prevalent defect and second primary molars as the most frequently affected teeth. Studies have shown that, in primary teeth, there are specific groups (e.g., second primary molars) more commonly affected by enamel defects, more specifically by demarcated opacities. ${ }^{36,37}$ The prevalence of HSPM ranges from 0 to $21.8 \%$ among studies conducted in different countries. ${ }^{7}$

There is no study evaluating the relationship between MIH and ethnic groups. In the present study, Asian children presented a higher prevalence of MIH than did Caucasian children. To the best of our knowledge, this is the first study to show the relationship between DDE and different ethnic groups. Although the sample of this study is representative of the population of schoolchildren, these results should be interpreted with caution, because the number of Asian children (1.50\% of the study population) is small in our population. This suggests that future studies could investigate whether there is a predisposition to DDE among different ethnic groups that could be related to genetic alterations. 
Demarcated opacity in primary teeth increases the prevalence of molar incisor hypomineralization

\section{Conclusion}

MIH prevalence in the present study was $12.1 \%$. Each primary tooth with demarcated opacity increased the prevalence of MIH by
$33 \%$, suggesting that demarcated opacity in primary teeth can be a strong predictor of $\mathrm{MIH}$ in the future permanent dentition. Also, Asian children had a higher prevalence of $\mathrm{MIH}$ than did Caucasian children.

\section{References}

1. Weerheijm KL, Jälevik B, Alaluusua S. Molar-incisor hypomineralisation. Caries Res. 2001 Sep-Oct;35(5):390-1. https://doi.org/10.1159/000047479

2. Jälevik B, Klingberg G. Treatment outcomes and dental anxiety in 18-year-olds with $M I H$, comparisons with healthy controls - a longitudinal study. Int J Paediatr Dent. 2012 Mar;22(2):85-91. https://doi.org/10.1111/j.1365-263X.2011.01161.x

3. Soviero V, Haubek D, Trindade C, Da Matta T, Poulsen S. Prevalence and distribution of demarcated opacities and their sequelae in permanent 1st molars and incisors in 7 to 13-year-old Brazilian children. Acta Odontol Scand. 2009;67(3):170-5. https://doi.org/10.1080/00016350902758607

4. Zhao D, Dong B, Yu D, Ren Q, Sun Y. The prevalence of molar incisor hypomineralization: evidence from 70 studies. Int J Paediatr Dent. 2018 Mar;28(2):170-9. https://doi.org/10.1111/ipd.12323

5. Elfrink ME, ten Cate JM, Jaddoe VW, Hofman A, Moll HA, Veerkamp JS. Deciduous molar hypomineralization and molar incisor hypomineralization. J Dent Res. 2012 Jun;91(6):551-5. https://doi.org/10.1177/0022034512440450

6. Sé MJSF, Ribeiro AP, Santos-Pinto LA, Cordeiro RCL, Cabral RN, Leal SC. Are hypomineralized primary molars and canines associated with molar-incisor hypomineralization? Pediatr Dent. 2017 Nov;39(7):445-9.

7. Elfrink ME, Ghanim A, Manton DJ, Weerheijm KL. Standardised studies on Molar Incisor Hypomineralisation (MIH) and Hypomineralised Second Primary Molars (HSPM): a need. Eur Arch Paediatr Dent. 2015 Jun;16(3):247-55. https://doi.org/10.1007/s40368-015-0179-7

8. Mittal N, Sharma BB. Hypomineralised second primary molars: prevalence, defect characteristics and possible association with molar incisor hypomineralisation in Indian children. Eur Arch Paediatr Dent. 2015 Dec;16(6):441-7. https://doi.org/10.1007/s40368-015-0190-z

9. Temilola OD, Folayan MO, Oyedele T. The prevalence and pattern of deciduous molar hypomineralization and molarincisor hypomineralization in children from a suburban population in Nigeria. BMC Oral Health. 2015 Jun;15(1):73. https://doi.org/10.1186/s12903-015-0059-x

10. Carvalho JC, Silva EF, Gomes RR, Fonseca JA, Mestrinho HD. Impact of enamel defects on early caries development in preschool children. Caries Res. 2011;45(4):353-60. https://doi.org/10.1159/000329388

11. Butler PM. Dental merism and tooth development. J Dent Res. 1967 Sep-Oct;46(5):845-50. https://doi.org/10.1177/00220345670460053801PMID:5234023

12. Weerheijm KL. Molar incisor hypomineralisation (MIH). Eur J Paediatr Dent. 2003 Sep;4(3):114-20.

13. Garot E, Denis A, Delbos Y, Manton D, Silva M, Rouas P. Are hypomineralised lesions on second primary molars (HSPM) a predictive sign of molar incisor hypomineralisation (MIH)? A systematic review and a meta-analysis. J Dent. 2018 May;72:8-13. https://doi.org/10.1016/i.jdent.2018.03.005

14. Jeremias F, de Souza JF, Silva CM, Cordeiro RC, Zuanon AC, Santos-Pinto L. Dental caries experience and Molar-Incisor Hypomineralization. Acta Odontol Scand. 2013 May-Jul;71(3-4):870-6. https://doi.org/10.3109/00016357.2012.734412

15. Jälevik B, Klingberg GA. Dental treatment, dental fear and behaviour management problems in children with severe enamel hypomineralization of their permanent first molars. Int J Paediatr Dent. 2002 Jan;12(1):24-32. https://doi.org/10.1046/i.0960-7439.2001.00318.x

16. Fagrell TG, Dietz W, Jälevik B, Norén JG. Chemical, mechanical and morphological properties of hypomineralized enamel of permanent first molars. Acta Odontol Scand. 2010 Jul;68(4):215-22. https://doi.org/10.3109/00016351003752395

17. Garcia-Margarit M, Catalá-Pizarro M, Montiel-Company JM, Almerich-Silla JM. Epidemiologic study of molar-incisor hypomineralization in 8-year-old Spanish children. Int J Paediatr Dent. 2014 Jan;24(1):14-22. https://doi.org/10.1111/ipd.12020

18. Instituto Brasileiro de Geografia e Estatística - IBGE. Censo 2010. Rio de Janeiro, RJ: Instituto Brasileiro de Geografia e Estatística; 2010.

19. A review of the developmental defects of enamel index (DDE Index). Commission on Oral Health, Research \& Epidemiology. Report of an FDI Working Group. Int Dent J. 1992 Dec;42(6):411-26. 
20. Weerheijm KL, Duggal M, Mejàre I, Papagiannoulis L, Koch G, Martens LC, et al. Judgement criteria for molar incisor hypomineralisation $(\mathrm{MIH})$ in epidemiologic studies: a summary of the European meeting on MIH held in Athens, 2003. Eur J Paediatr Dent. 2003 Sep;4(3):110-3.

21. Seow WK. Clinical diagnosis of enamel defects: pitfalls and practical guidelines. Int Dent J. 1997 Jun;47(3):173-82. https://doi.org/10.1002/i.1875-595X.1997.tb00783.x

22. Costa-Silva CM, Jeremias F, Souza JF, Cordeiro RC, Santos-Pinto L, Zuanon AC. Molar incisor hypomineralization: prevalence, severity and clinical consequences in Brazilian children. Int J Paediatr Dent. 2010 Nov;20(6):426-34. https://doi.org/10.1111/j.1365-263X.2010.01097.x

23. Muratbegovic A, Markovic N, Ganibegovic Selimovic M. Molar incisor hypomineralisation in Bosnia and Herzegovina: prevalence, aetiology and clinical consequences in medium caries activity population. Eur Arch Paediatr Dent. 2007;8(4):189-94. https://doi.org/10.1007/BF03262595

24. Ng JJ, Eu OC, Nair R, Hong CH. Prevalence of molar incisor hypomineralization (MIH) in Singaporean children. Int J Paediatr Dent. 2015 Mar;25(2):73-8. https://doi.org/10.1111/ipd.12100

25. Ahmadi R, Ramazani N, Nourinasab R. Molar incisor hypomineralization: a study of prevalence and etiology in a group of Iranian children. Iran J Pediatr. 2012 Jun;22(2):245-51.

26. Folayan MO, Oyedele TA, Oziegbe E. Time expended on managing molar incisor hypomineralization in a pediatric dental clinic in Nigeria. Braz Oral Res. 2018 Aug;32(0):e79. https://doi.org/10.1590/1807-3107bor-2018.vol32.0079

27. Fragelli CMB, Jeremias F, Souza JF, Paschoal MA, Cordeiro RCL, Santos-Pinto L. Longitudinal Evaluation of the Structural Integrity of Teeth Affected by Molar Incisor Hypomineralisation. Caries Res. 2015;49(4):378-83. https://doi.org/10.1159/000380858

28. Neves AB, Americano GC, Soares DV, Soviero VM. Breakdown of demarcated opacities related to molar-incisor hypomineralization: a longitudinal study. Clin Oral Investig. 2019 Feb;23(2):611-5. https://doi.org/10.1007/s00784-018-2479-x

29. Ghanim A, Manton D, Mariño R, Morgan M, Bailey D. Prevalence of demarcated hypomineralisation defects in second primary molars in Iraqi children. Int J Paediatr Dent. 2013 Jan;23(1):48-55. https://doi.org/10.1111/j.1365-263X.2012.01223.x

30. Cho SY, Ki Y, Chu V. Molar incisor hypomineralization in Hong Kong Chinese children. Int J Paediatr Dent. 2008 Sep;18(5):348-52. https://doi.org/10.1111/j.1365-263X.2008.00927.x

31. Allazzam SM, Alaki SM, El Meligy OA. Molar incisor hypomineralization, prevalence, and etiology. Int J Dent. 2014;2014:234508. https://doi.org/10.1155/2014/234508

32. Oyedele TA, Folayan MO, Adekoya-Sofowora CA, Oziegbe EO, Esan TA. Prevalence, pattern and severity of molar incisor hypomineralisation in 8- to 10-year-old school children in Ile-Ife, Nigeria. Eur Arch Paediatr Dent. 2015 Jun;16(3):277-82. https://doi.org/10.1007/s40368-015-0175-y

33. Leppäniemi A, Lukinmaa PL, Alaluusua S.. Nonfluoride hypomineralizations in the permanent first molars and their impact on the treatment need. Caries Res. 2011;35:36-40. https://doi.org/10.1159/000047428

34. Mittal NP, Goyal A, Gauba K, Kapur A. Molar incisor hypomineralisation: prevalence and clinical presentation in school children of the northern region of India. Eur Arch Paediatr Dent. 2014 Feb;15(1):11-8. https://doi.org/10.1007/s40368-013-0045-4

35. Lygidakis NA, Wong F, Jälevik B, Vierrou AM, Alaluusua S, Espelid I. Best Clinical Practice Guidance for clinicians dealing with children presenting with Molar-Incisor-Hypomineralisation (MIH): An EAPD Policy Document. Eur Arch Paediatr Dent. 2010 Apr;11(2):75-81. https://doi.org/10.1007/BF03262716

36. Robles MJ, Ruiz M, Bravo-Perez M, González E, Peñalver MA. Prevalence of enamel defects in primary and permanent teeth in a group of schoolchildren from Granada (Spain). Med Oral Patol Oral Cir Bucal. 2013 Mar; 18(2):e187-93. https://doi.org/10.4317/medoral.18580

37. Slayton RL, Warren JJ, Kanellis MJ, Levy SM, Islam M. Prevalence of enamel hypoplasia and isolated opacities in the primary dentition. Pediatr Dent. 2001 Jan-Feb;23(1):32-6. 